\title{
DEVELOPMENT OF A SYSTEM DYNAMICS MODEL FOR SUSTAINABLE LAND USE MANAGEMENT
}

\author{
Chien-Hwa $\mathrm{Yu}^{*}$, Ching-Ho Chen, Cheng-Fang Lin and Shiu-Liang Liaw
}

\begin{abstract}
The current land use management framework considers economic, social, and environmental influences individually, making it difficult to achieve sustainable development. Therefore, this study aims to develop a system dynamics model to help decision makers to integrally and systematically consider the components and interactions in land use management. Based on the concept of sustainable development, this study uses systems thinking to develop dynamics of sustainable land use management in a river basin, which considers human activities, land resources, water resources, and air resources integrally. Furthermore, this study uses the concept of driving forcestate-response to establish a conceptual dynamics framework for sustainable land use management. Because of the complicated interactions among the above components and iterative decision-making procedures, this study uses Vensim software and the concept of object-oriented programming to develop a sustainable land use management system dynamics model (SLUMSD model) based on the conceptual dynamics framework. The Nankan river basin is used as a case study to illustrate the capability of the SLUMSD model. The case study indicates that the interactions among the components in sustainable land use management can be effectively identified in the SLUMSD model. While planning strategies for sustainable land use management, decision-makers can use the SLUMSD model to understand how the components vary with different alternatives. Using the SLUMSD model to iteratively modify alternatives can ensure appropriate decision-making in sustainable land use management.
\end{abstract}

Key Words: sustainable land use management, systems thinking, D-S-R framework, object-oriented programming, system dynamics model.

\section{INTRODUCTION}

Land resources are necessary and important for human development. Inadequate land use management causes serious environmental impacts. In Taiwan, the land use management framework was originally based on urban and regional plans. The

*Corresponding author. (Tel: 886-3-3325848; Fax: 886-33320729; Email: jhyou@ms18.hinet.net)

C. H. Yu and C. F. Lin are with the Graduate Institute of Environmental Engineering, National Taiwan University, Taipei, Taiwan 106 , R.O.C.

C. H. Chen is with the Department of Civil Engineering, Nanya Institute of Technology, Chungli, Taiwan 320, R.O.C.

S. L. Liaw is with the Graduate Institute of Environmental Engineering, National Central University, Chungli, Taiwan 320, R.O.C. relevant regulations were implemented in the 1960s. Environmental protection agencies were included in the planning procedures in the 1990s as pollution became a growing problem. Under the procedures, environmental impact assessments must be performed for various development activities. The main purpose of the environmental impact assessment phase of the procedure is to prevent and mitigate the adverse environmental impacts of developmental activities (Liu, 1997). However, economic, social, and environmental impacts are analyzed separately in the current land use management framework. In some practical cases, the consequence is often traffic congestion, poor environmental quality and town cramming (Williams, 1999). It is necessary to improve and modify the current land use management framework to pursue sustainable development. 
Sustainable development may be regarded as the progressive and balanced achievement of sustained economic development, improved social equity and environmental sustainability (Luxem and Bryld, 1997). Economic, social and environmental factors and impacts must be assessed together in sustainable land use management. Because the components are numerous and the interactions among the components are complicated in land use management, this study uses systems thinking to obtain integral and complete analytical results.

The approach of systems thinking is an analytical method proposed by Forrester in 1961, which focuses on how the thing being studied interacts with the other components of the system. System dynamics was proposed to achieve systems thinking with computer models in solving complicated management problems. In 1972, Meadows used the theory to develop Limit to Growth models to discuss the impact of population growth, pollution, and resource use on the planet (Senge, 1990). Since ecosystems involve complicated interactions, recent years have seen the development of many system dynamics models for ecosystems (Costanza et al., 1998; Saysel and Barlas, 2001). It is important and useful to develop a system dynamics model for land use management.

This study aims to develop a sustainable land use management system dynamics model (SLUMSD model). In the beginning, this study identifies the concept of sustainable land use management by using the concept of carrying capacity. Systems thinking is used to develop dynamics of sustainable land use management in a river basin, considering human activities, land resources, water resources, and air resources integrally. The concept of driving forcestate-response is used to establish a conceptual $\mathrm{dy}$ namics framework for sustainable land use management. The Vensim software and the concept of object-oriented programming are used to build the SLUMSD model. Finally, the Nankan river basin, located in northern Taiwan, is used to illustrate the capability of the SLUMSD model. The results show that the SLUMSD model developed in this study can be used to help land use management decision makers to achieve sustainable development.

\section{CONCEPT OF SUSTAINABLE LAND USE MANAGEMENT}

Land resources are necessary to human development. Inefficient use of land resources can not support human development. However, scarcity of land resources creates competition among development activities. The needs of various stakeholders must be considered and balanced for sustainable development.
The concept of sustainable land use has recently been discussed in different studies. Land characteristics have been considered to determine the appropriate development activities. For example, a fertile plain is suitable for agricultural development, while a steep mountain slope is unsuitable for residential development. Consideration of this issue can prevent land being damaged through inappropriate development activities (Senes and Toccolini, 1998; Li et al., 2001). Furthermore, the influence of resources supply on land use plans has also been considered. For example, total agricultural land use must be enough to ensure an adequate food supply (van Ittersum et al., 1998). Additionally, ecological impact has been assessed during land development. The land development plan must be controlled to mitigate ecological impact to an acceptable level (Miyamoto et al., 1996; Zander and Kächele, 1999). Furthermore, sustainable land use development may be influenced by economic benefit. Environmental impact is suggested as a cost item in land development. Land use plans can be considered sustainable when their total economic benefit is sustainable (Teague, 1996).

According to the discussions of sustainable development (WCED, 1987; IUCN/UNEP/WWF, 1991), this study identifies the principles of sustainable land use management as three important concepts: (1) meeting the needs of humans to survive and develop; (2) keeping within the land's carrying capacity; and (3) using systems thinking in the procedure.

Because studies have differed in their definitions of the carrying capacity of ecosystems (Chen et al., 1997), this study uses sound levels of resource use and pollutant concentration to identify the concept of carrying capacity, which means that total water demand must be less than total available water quantity, and river water quality and air quality must meet regulatory standards. These are constraints in sustainable land use management.

The related factors in land use management are numerous and the interactions among the factors are complicated. Individually, analyses and plans can not consider integral influences, so sustainable development is hard to achieve. Development activities influence each other. Environmental factors also influence each other. The systems thinking approach is suitable to use to analyze the components and interactions in sustainable land use management so that one can obtain integral and complete results.

\section{DYNAMICS OF SUSTAINABLE LAND USE MANAGEMENT}

This study uses the concepts and procedures of system analysis to develop dynamics of sustainable land use management. The development procedures 


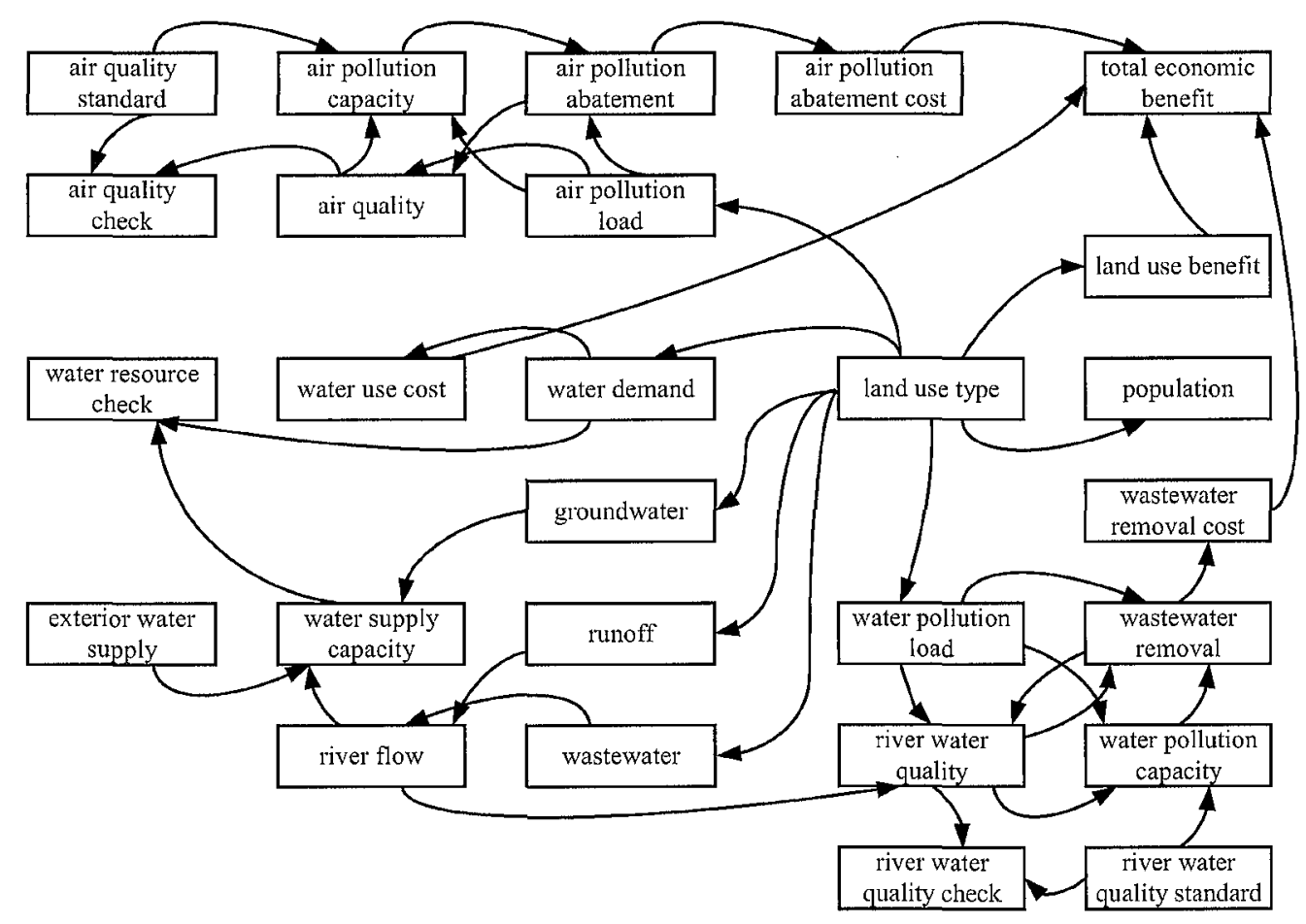

Fig. 1 Interaction framework of sustainable land use management

include (1) identification of system and components, (2) identification of relationships and interactions, and (3) the conceptual dynamics framework.

\section{Identification of System and Components}

A river basin is considered to be an appropriate spatial unit for sustainable land use management. The boundaries of a river basin environment system are usually drawn geographically rather than politically. In this study, a river basin can be conceptually divided into drainage zones based on geographical characteristics. The territory of each drainage zone is primarily based on a natural branch, natural tributary, or artificial discharger (Buller, 1996; Chen et al., 1997).

All of the components in the system, which are related to sustainable land use management, should be considered. However, based on the capabilities of data collection and the knowledge of interactive mechanisms, this study simplifies the principal components of the system as land resources, water resources, air resources, and human activities. The attributes of land resources include land area and land use type, with the latter being divided into six broad categories: residential-commercial, industrial, paddy, dry farming, forest, and other land use. The attributes of water resources include the quantity and quality of surface and ground waters, while the attributes of air resources include the air quality. Finally, the attributes of human activities include development activities and management instruments.

\section{Identification of Relationship and Interactions}

The interactions involved in sustainable land use management can be classified into two groups. The first group includes interactions between human activities and environmental resources. For example, human activities require land and water resources. Furthermore, human activities also alter land use types, and generate waste, which is emitted into the environmental media, including the water, air and land. Management instruments, such as environmental quality standards and resource use limits, are developed based on the state of the environment, and humans also engage in activities such as pollution control and resource allocation.

The second group of interactions includes those among human activities and those among environmental resources. Human activities naturally influence each other, and substances move among different environmental resources and spatial positions.

This study establishes the interaction structure of sustainable land use management, shown in Fig. 1. Each block of the structure represents a component and the arrows link components if interaction exists between them. Components which influence 


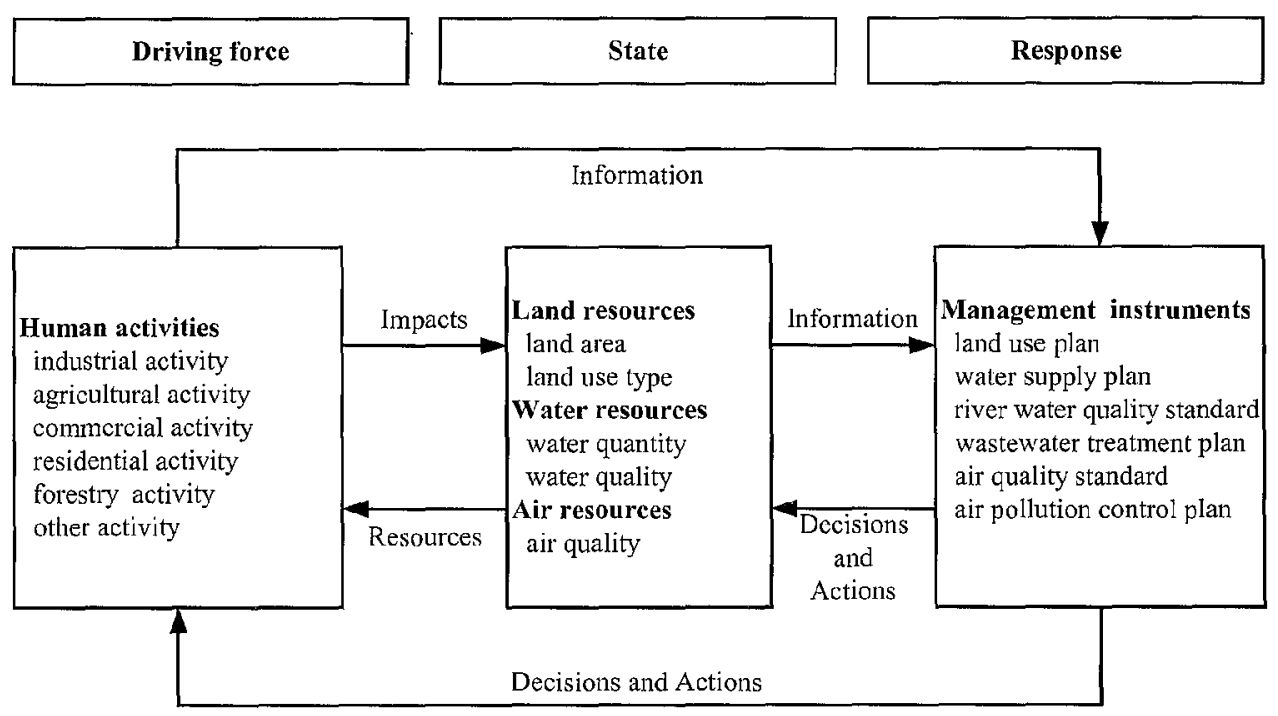

Fig. 2 Conceptual dynamics framework for sustainable land use management

others are at the start of arrows, while components which are influenced by others are at the end of arrows. For example, available water quantity is influenced by quantity of river flow, groundwater, and exterior water supply. Meanwhile, available water quantity influences the result of water quantity sufficiency checks.

Concerning land resources, areas of land and land use types are allocated for the needs of human activities. The benefit of land use is influenced by the attributes of the land. For water resources, land attributes influence the water demand, groundwater, runoff, wastewater and water pollution load. Available water quantity is influenced by the flows of groundwater and river water. River water quality is influenced by the river water flow, water pollution load and wastewater removal. The cost of wastewater removal is influenced by the quantity of wastewater removal. For air resources, land attributes influence the air pollution load. Air quality is influenced by the air pollution load and air pollution abatement. The cost of air pollution abatement is influenced by the quantity of air pollution.

\section{The Conceptual Dynamics Framework}

To think of the interactions in land use management as an integrated system, the concept of driving force-state-response (D-S-R) framework can be used to establish a conceptual dynamics framework for sustainable land use management. The D-S-R framework was adopted by the United Nations Commission on Sustainable Development (CSD) as a tool for organizing information on sustainable development and also for developing, presenting, and analyzing indicators of sustainable development. Generally, the driving forces of sustainable development include human activities, processes, and patterns that will have an impact on sustainable development, whether positively or negatively. The states are the situation of the environment and natural resources, or particular aspects of them, at a given point in time. They pertain to qualitative and/or quantitative description. The responses to changes in the state of sustainable development can be legislation, regulation, economic instruments, information activities and so on (Mortensen, 1997; Chen et al., 2000). Moreover, the D-S-R framework includes causal relationships for decision-making.

The framework, shown in Fig. 2, concisely describes all of the principal components and interactions involved in sustainable land use management. The driving forces of sustainable land use management include various human activities. The states are the situations of land resources, water resources and air resources. Furthermore, the responses to changes in the state of sustainable land use management can be management instruments applicable to the driving forces and the states. All of the components in the dynamics framework influence each other.

In the framework, different stakeholders manage parts of the components. In sustainable land use management, the needs of stakeholders can be stated as alternatives and applied in the framework. After interacting, the variations of components and their influenced results can be seen integrally. According to the results, each stakeholder can modify his alternative to be close to the objective. After modifying iteratively, the alternative fitting the concept of sustainable land use management can be obtained. 


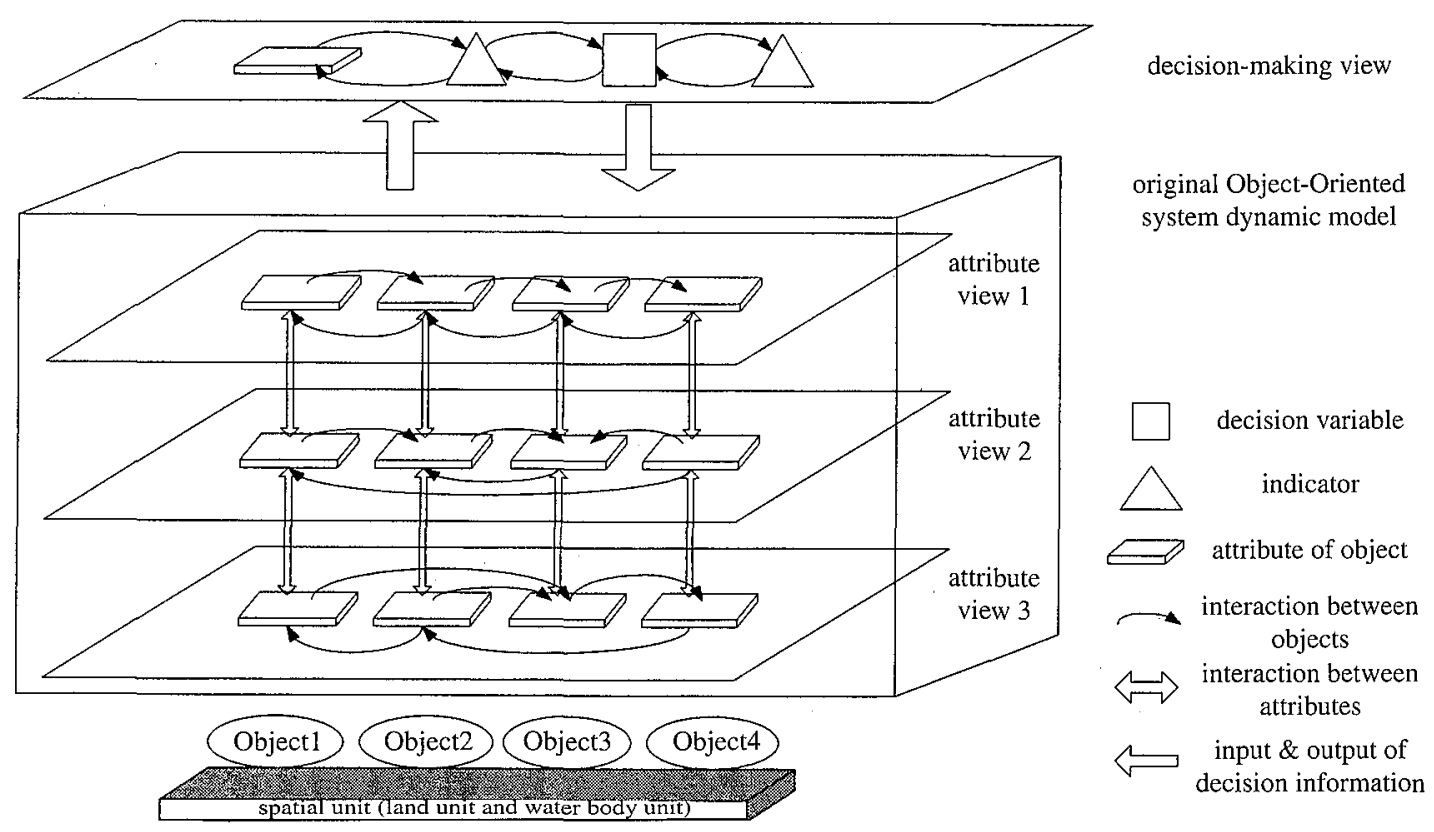

Fig. 3 Conceptual object-oriented structure for sustainable land use management ( $\mathrm{Li}, 2002)$

\section{THE SUSTAINABLE LAND USE MANA GEMENT SYSTEM DYNAMICS MODEL}

Based on the conceptual dynamics framework and interactions, this study develops a sustainable land use management system dynamics model (SLUMSD model) using the software Vensim 4.0a and the concept of object-oriented programming (OOP).

Vensim is a powerful tool for building a system dynamics model, and combines the editing functions of a graphics interface with a programming language. In Vensim, the modeling window is called a "view", and models can be separately built in different views. All work done in different views can be automatically composed into an integral model by linking variables while using the internal functions of Vensim. In the SLUMSD model, when any variable is altered, the influence on other variables can be seen. Similarly, the model can show what variables cause the influenced result. Because the components are numerous and the interactions are complicated, and the results must be considered integrally, it is suitable to use Vensim to develop system dynamics models for sustainable land use management.

The modeling method is made more powerful by combining it with the concept of OOP. Land use management sees land units as objects, and sees their characteristics and resources as object attributes. Meanwhile, water body units are seen as different kind of objects. Attributes and processes are encapsulated in objects and thus their definitions and modifications are independent. During modeling, interactions among objects for an identical attribute are built using a specific view. Meanwhile, interactions among attributes for an identical object are built in the implicit structure.

Figure 3 displays the conceptual object-oriented structure for sustainable land use management. In the structure, attributes are placed above the object to which they belong, and attributes of the same kind are placed on the same plain. Meanwhile, horizontal arrows represent interactions among objects for an identical attribute. For example, the water supply capacities of all the drainage zones influence one another during allocation. Meanwhile, vertical arrows represent interactions among attributes for an identical object. For example, the air quality of an identical drainage zone is influenced by its air pollution load, which in turn is influenced by both the land use types and the area of the drainage zone. Through chain reactions, variation of any component influences all other components in the structure. Furthermore, attributes can be selected as decision variables or indicators to compose a new view for decision-making, without modifying the original structure.

The SLUMSD model can be modified or expanded easily using the concept of OOP. If the system boundaries expand, the SLUMSD model only requires adding some new objects. Meanwhile, if more attributes are considered, the SLUMSD model only requires adding new views. SLUMSD model modification and expansion do not require that the 


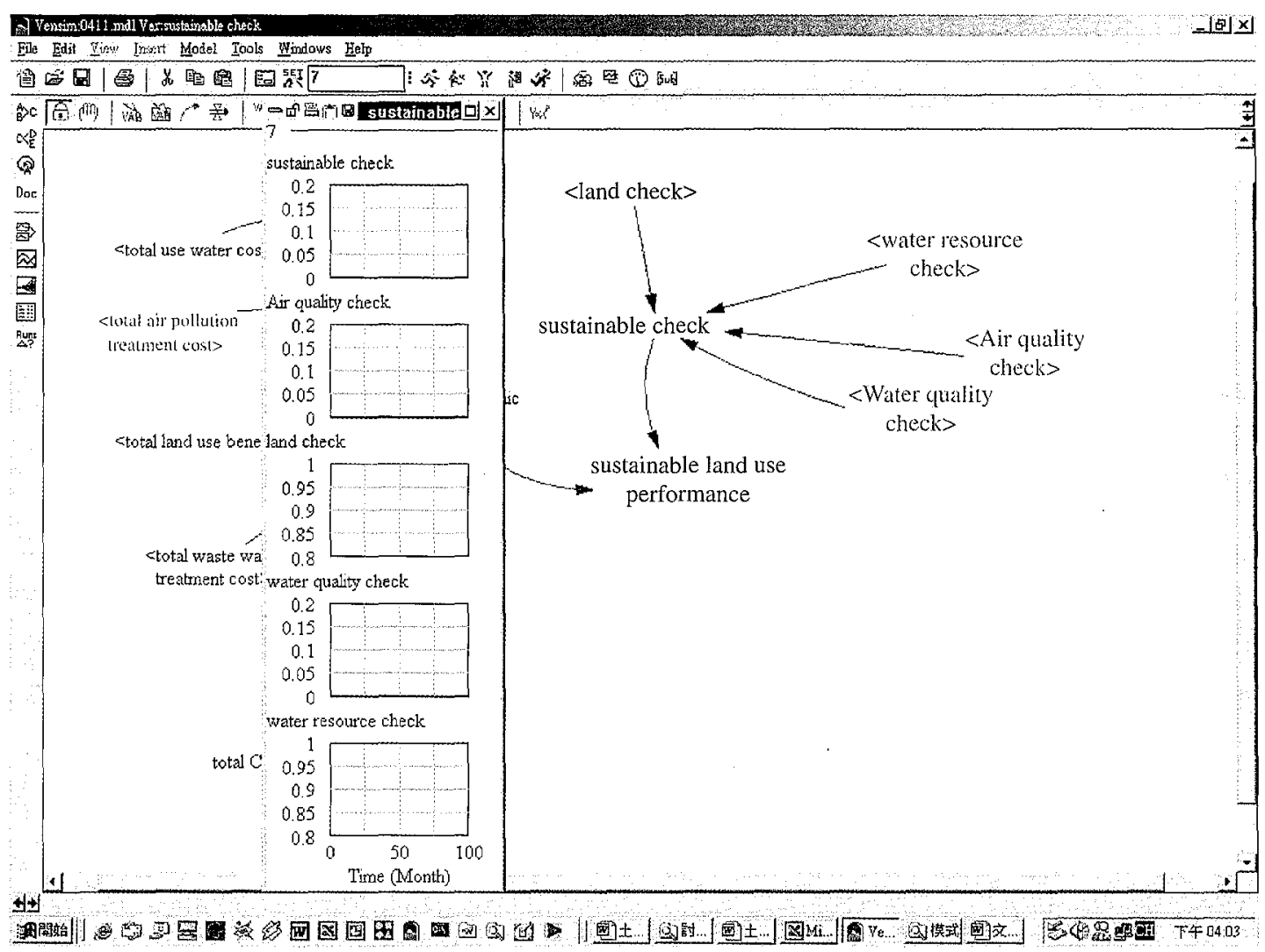

Fig. 4 Sustainability assessment window of the model

structure be rebuilt. The SLUMSD model makes the following assumptions.

(1) Each land use type has its own unit levels of water demand, water pollution load, air pollution load, land use benefit, and population density.

(2) The costs of water use, wastewater removal, and air pollution abatement are assumed to be unit costs.

(3) The total benefit is the summation of the land use benefit, and water use, wastewater removal, and air pollution abatement costs.

(4) The river water quality simulation is based on the Streeter-Phelps equation and the related assumptions (Streeter and Phelps, 1925). The indices of water quality include BOD and DO.

(5) The air quality simulation is based on the roll back equation and the related assumptions (Nevers, 1995). Individual air pollutants include PM10, SOx, NOx, and NMHC.

The SLUMSD model can display all assessed sustainability results simultaneously, as shown in Fig. 4, which includes land resources, water resources, river water quality, and air quality. The result value shows 1 if the item meets the principles of sustainable land use management, otherwise 0 .

In the process of evaluating alternatives, the
SLUMSD model can be used to show the influencing components and the influenced components in the causal loops, as shown in Fig 5. Therefore, the model user can vary any component and then obtain all of the corresponding influence to other components simultaneously. Similarly, the model user can obtain desired results by varying the influencing components.

The SLUMSD model employs sliders to modify the input data in various management plans, as shown in Fig. 6. Using this function, the model user can see how input data variation causes corresponding variation in the analytical results.

The policy optimization function in Vensim can be applied as the optimization method in this study. In order to use optimization, model users must define the payoff first. The payoff is a measure, reported at the end of the simulation, stating numerically how good the simulation was. The payoff can consist of one or several components, to which users can give weights. For example, the payoff can be the summation of total benefits, which are given equal weights. After defining the payoff, users must select some components and give them maximum and minimum bounds. At the end of optimization, Vensim can give users the maximum payoff and the values of 


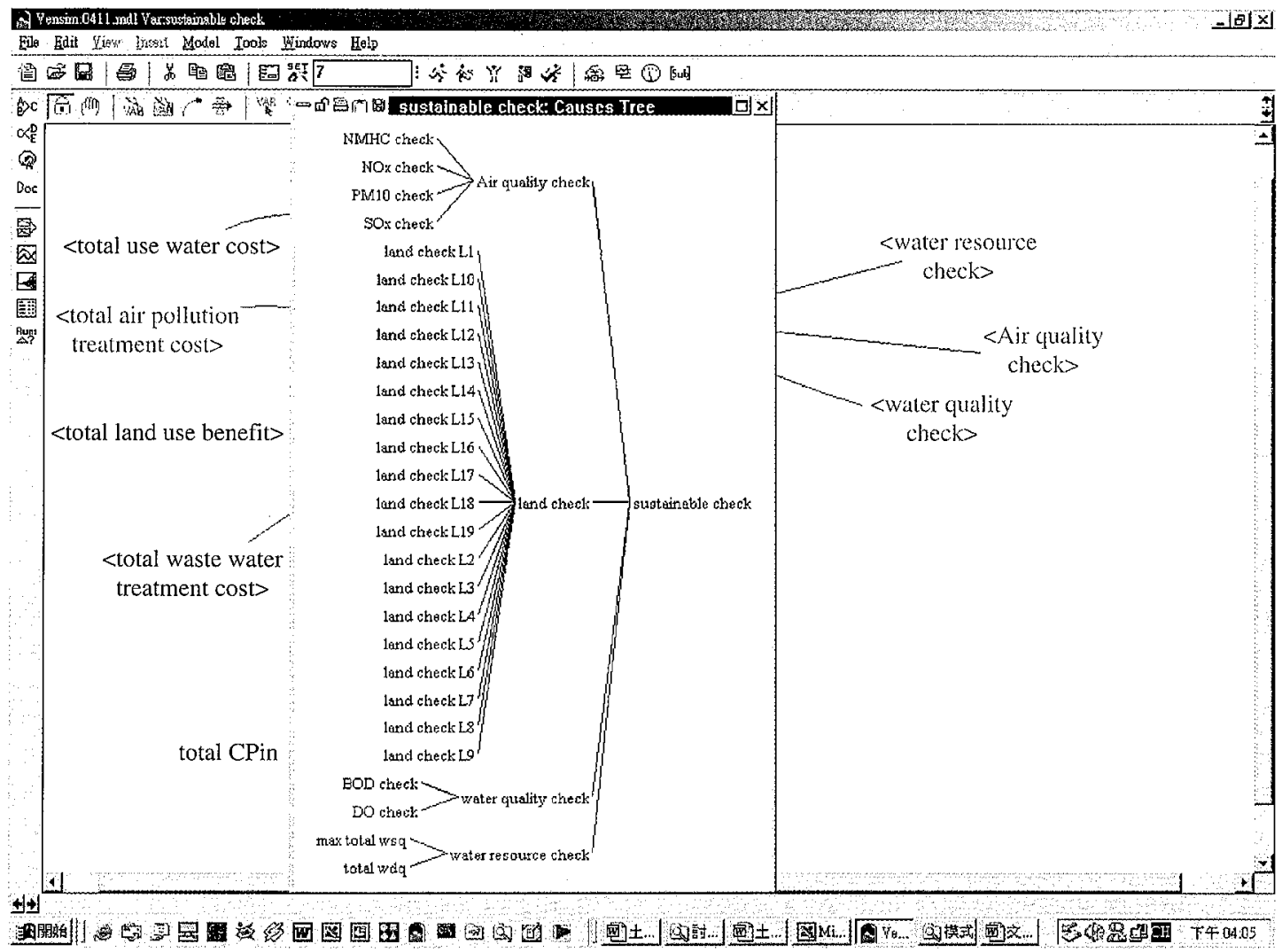

Fig. 5 Causal loop window of the model

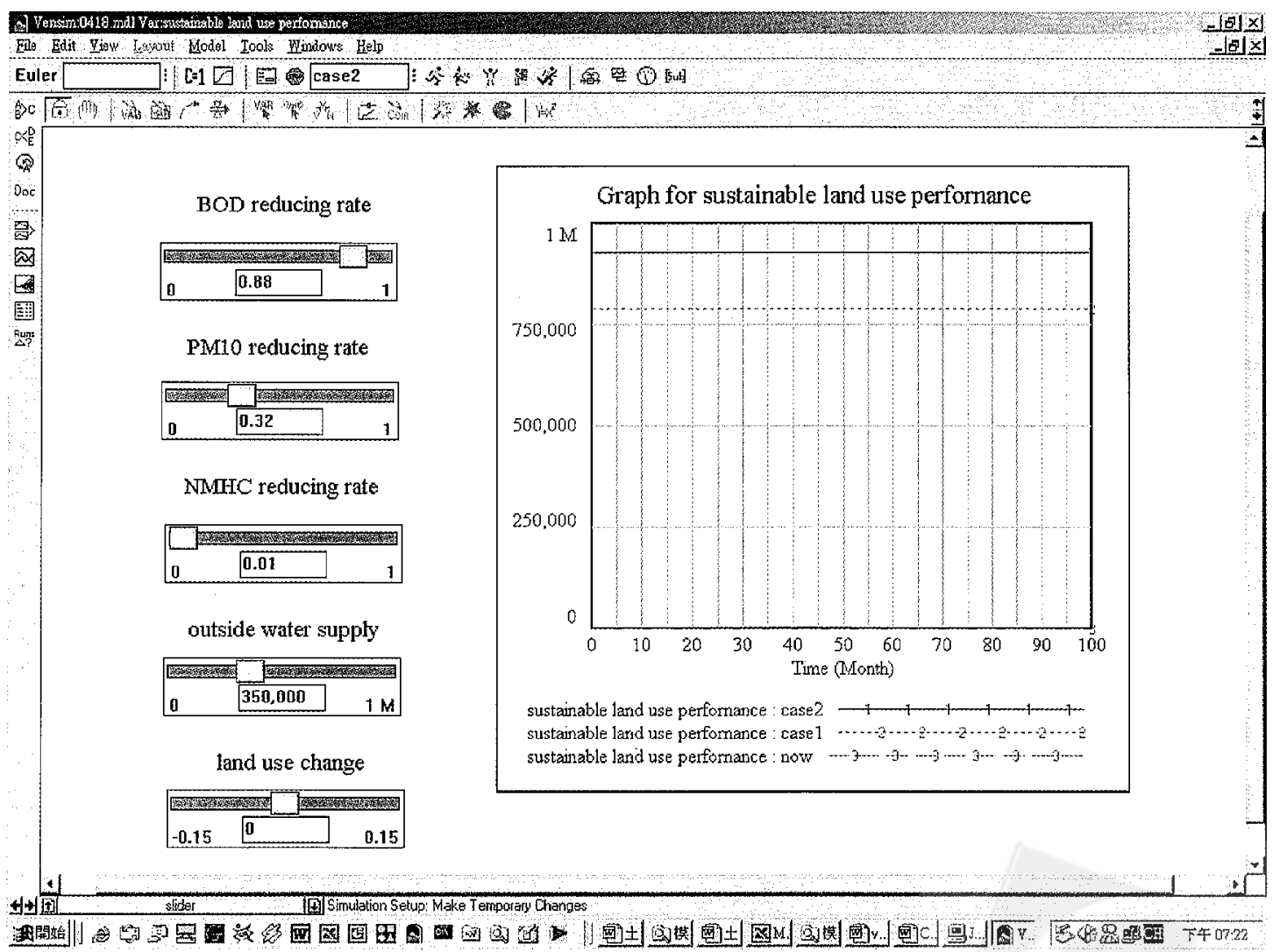

Fig. 6 Sliders and graph window of the model 


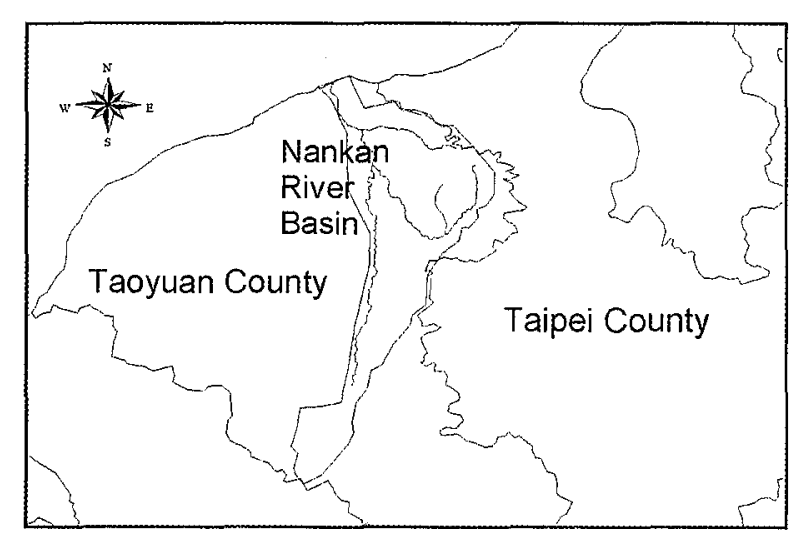

Fig. 7 Location of the Nankan river basin

all components.

\section{CASE STUDY}

The Nankan river basin, located in northern Taiwan, is used as a practical case to illustrate the capability of the SLUMSD model. The total basin area is $214.67 \mathrm{~km}^{2}$, while the main stream is 30.73 $\mathrm{km}$ long. Location of the Nankan river basin is shown in Fig. 7. The basin has been highly developed by various human activities.

\section{Assessment of the Current Condition of the Nankan River Basin}

According to EPA research, the Nankan river basin is divided into 19 drainage zones and 18 reaches (EPA, 1991). Therefore, the SLUMSD model developed in this study includes 19 land objects, and 18 water body objects. This study uses geographic information system (GIS) data to obtain the total area of each land use type in each drainage zone of the basin, and then works out the portion of total land area that each land use type represents. GIS data includes the results of land use surveys by the Department of Land Administration of the Taiwan Provincial Government, the range of the basin, and the range of the drainage zones. Meanwhile, other input data are adopted from related studies (EPA, 1991; Yu et al., 2001; Li, 2002). Tables 1 to 5 illustrate the input data of land use, hydraulics, water resource, water pollution, air pollution, society and economics. Hydraulics data is based on the condition of annual average flow. Furthermore, the costs of water use for the public, industry, and agriculture are 7.0,6.4, and $0.2 \mathrm{NT} \$ / \mathrm{m}^{3}$. The costs of water pollution abatement for the public and industry are 8 and 5 NT\$/kg-BOD. The costs of air pollution abatement for PM10, SOx, NOx, and NMHC are 12, 15, 21, 18 NT\$/kg.

According to the assessed results, total water demand is $8.27 \times 10^{5} \mathrm{~m}^{3}$, which is more than the total available water quantity in the basin. Moreover, the highest BOD and the lowest DO concentration of the river are $28.7 \mathrm{mg} / 1$ and $2.6 \mathrm{mg} / 1$, which both fail to meet river water quality standards. Additionally, the highest PM10 concentration of the basin system is $81.1 \mu \mathrm{g} / \mathrm{Nm}^{3}$, which fails to meet air quality standards. Given that present land use conditions in the Nankan river basin can not meet the principles of sustainable land use management, an appropriate sustainable land use management strategy must be planned for the basin.

\section{Strategic Planning for Sustainable Land Use Management}

The Nankan river basin contains 1,928 hectares of industrial land use, representing $9.0 \%$ of the total area of the basin. It is complicated to determine what area of industrial land use in the Nankan river basin is appropriate for sustainable development. For the development needs, the area of industrial land use is considered to increase. However, the area of industrial land use needs to decrease if considering mitigating environmental impacts.

This study uses the concept of sustainable land use management and the SLUMSD model to generate optimal land use management strategy. The variations of the total area of industrial land use have been assumed as seven options: $0 \%,+5 \%,+10 \%,+15 \%$, $-5 \%,-10 \%$, and $-15 \%$. As discussed above, based on the concept of sustainable land use management, human activities, land resources, water resources and air resources should be considered together. The management strategies are discussed as followed.

(1) The increasing area of industrial land use is transformed from the area of paddy, dry farming, and forestry land use. The decreasing area of industrial land use is transformed into areas of other land uses. This study simplifies the transforming ratio to be the same in all of the drainage zones.

(2) The strategy of available water quantity allocation involves increasing available water quantity from outside the Nankan river basin since it is very difficult to increase available water quantity in the basin. According to the concept of carrying capacity, total water demand of the basin must be less than total available water quantity.

(3) The strategy of water quality management aims to abate BOD load in wastewater. Many different methods can be used to abate BOD load. However, this case study uses the equal-abating-rate method, meaning that the BOD load from each drainage zone and wastewater source is abated the same rate for the sake of equity. According to the concept of carrying capacity, the BOD and DO 
Table 1 Land use data of drainage zones

\begin{tabular}{crccccccc}
\hline No. & $\begin{array}{c}\text { Area } \\
\text { (ha) }\end{array}$ & Residential & Industrial & Paddy & Dry Farm & Forest & Other & $\begin{array}{c}\text { Unit Runoff } \\
\text { (CMD/ha) }\end{array}$ \\
\hline 1 & 1,417 & 0.0912 & 0.0803 & 0.0000 & 0.0216 & 0.4794 & 0.3275 & 10 \\
2 & 1,210 & 0.0821 & 0.0573 & 0.0367 & 0.0283 & 0.0906 & 0.7050 & 10 \\
3 & 341 & 0.0630 & 0.1005 & 0.0015 & 0.0148 & 0.6405 & 0.1796 & 10 \\
4 & 189 & 0.2829 & 0.0525 & 0.0028 & 0.0104 & 0.1474 & 0.5040 & 10 \\
5 & 1,726 & 0.2885 & 0.1156 & 0.1244 & 0.0841 & 0.0112 & 0.3762 & 10 \\
6 & 209 & 0.1421 & 0.0125 & 0.0804 & 0.0005 & 0.0026 & 0.7619 & 22 \\
7 & 237 & 0.1929 & 0.0226 & 0.2279 & 0.0841 & 0.0000 & 0.4724 & 22 \\
8 & 445 & 0.0820 & 0.0563 & 0.0828 & 0.0509 & 0.2084 & 0.5196 & 22 \\
9 & 6,682 & 0.1252 & 0.0749 & 0.4416 & 0.0486 & 0.0048 & 0.3049 & 22 \\
10 & 1,681 & 0.0456 & 0.2605 & 0.0601 & 0.0568 & 0.2407 & 0.3363 & 22 \\
11 & 440 & 0.1254 & 0.2059 & 0.2724 & 0.0352 & 0.0008 & 0.3604 & 22 \\
12 & 245 & 0.0650 & 0.0893 & 0.6019 & 0.0130 & 0.0001 & 0.2306 & 22 \\
13 & 254 & 0.0476 & 0.2469 & 0.3199 & 0.0324 & 0.0238 & 0.3293 & 22 \\
14 & 2,338 & 0.0317 & 0.0171 & 0.1236 & 0.0604 & 0.3641 & 0.4031 & 22 \\
15 & 1,220 & 0.0785 & 0.0196 & 0.4579 & 0.0713 & 0.0059 & 0.3667 & 92 \\
16 & 539 & 0.0000 & 0.0000 & 0.5362 & 0.4293 & 0.0345 & 0.0000 & 92 \\
17 & 584 & 0.0500 & 0.0437 & 0.1802 & 0.0688 & 0.2506 & 0.4067 & 92 \\
18 & 320 & 0.1101 & 0.0978 & 0.2104 & 0.0517 & 0.1570 & 0.3730 & 92 \\
19 & 1,390 & 0.0518 & 0.1138 & 0.2688 & 0.1116 & 0.0912 & 0.3628 & 92 \\
\hline
\end{tabular}

Table 2 Hydraulic data of reaches (EPA, 1991)

\begin{tabular}{cccccc}
\hline No. & $\begin{array}{c}\text { Length } \\
(\mathrm{km})\end{array}$ & $\begin{array}{c}\text { Velocity } \\
(\mathrm{m} / \mathrm{sec})\end{array}$ & $\begin{array}{c}\text { Depth } \\
(\mathrm{m})\end{array}$ & $\begin{array}{c}\mathrm{K}_{1} \\
(1 / \text { day })\end{array}$ & $\begin{array}{c}\text { Classification } \\
\text { of quality } \\
\text { standards }\end{array}$ \\
\hline 1 & 5.00 & 0.60 & 0.15 & 0.3 & $\mathrm{C}$ \\
2 & 2.50 & 0.67 & 0.18 & 0.3 & $\mathrm{C}$ \\
3 & 2.50 & 0.73 & 0.21 & 0.3 & $\mathrm{C}$ \\
4 & 1.75 & 0.75 & 0.20 & 0.8 & $\mathrm{C}$ \\
5 & 1.50 & 0.85 & 0.25 & 0.8 & $\mathrm{C}$ \\
6 & 1.25 & 0.90 & 0.27 & 0.8 & $\mathrm{C}$ \\
7 & 1.00 & 1.22 & 0.48 & 0.6 & $\mathrm{C}$ \\
8 & 3.00 & 1.27 & 0.51 & 0.6 & $\mathrm{C}$ \\
9 & 1.00 & 1.03 & 0.32 & 0.6 & $\mathrm{C}$ \\
10 & 0.75 & 1.10 & 0.38 & 0.8 & $\mathrm{C}$ \\
11 & 1.25 & 1.13 & 0.40 & 0.8 & $\mathrm{C}$ \\
12 & 0.25 & 1.16 & 0.42 & 0.8 & $\mathrm{C}$ \\
13 & 0.75 & 1.19 & 0.44 & 0.8 & $\mathrm{C}$ \\
14 & 1.50 & 1.27 & 0.53 & 0.6 & $\mathrm{C}$ \\
15 & 1.50 & 1.34 & 0.57 & 0.1 & $\mathrm{C}$ \\
16 & 1.00 & 1.40 & 0.60 & 0.1 & $\mathrm{C}$ \\
17 & 1.00 & 1.45 & 0.64 & 0.1 & $\mathrm{C}$ \\
18 & 1.00 & 1.30 & 1.25 & 0.1 & $\mathrm{C}$ \\
\hline
\end{tabular}

concentrations of the river must meet the river water quality standards. Additionally, the technology constraint of abating rate is assumed as $90 \%$.

(4) The strategy of air quality management aims to abate PM10 and NMHC loads in waste air.
Similarly, the PM10 and NMHC loads from each drainage zone and emission source are abated at the same rate for the sake of equity. According to the concept of carrying capacity, the concentrations of PM10 and NMHC in the basin system must meet the air quality standards. Additionally, the technology constraint of abating rate is assumed as $80 \%$.

This study uses input sliders of the SLUMSD model to modify land area, abating rate of water pollution load, and abating rate of air pollution load and checks if these loads are within the carrying capacity. Moreover, this study modifies exterior available water quantity, river water quality, and air quality to obtain feasible alternatives. For each option of variation of area of industrial land use, numerous alternatives fitting the concept of sustainable land use management can be generated. Furthermore, this study uses the policy optimization function of the SLUMSD model to obtain each optimal solution for each option. The comparing criterion is the total benefit of alternative. Fig. 8 displays the results of the optimal benefits of all the options.

In this case, the increase in the area of industrial land use increases the benefit of land use, increases the cost of wastewater removal, increases the cost of air pollution abatement, and decreases the cost of water use. The overall result is a decrease in total benefit. Additionally, the total benefit increases when the decreasing ratio of the area of industrial land use is at or below $5 \%$. However, total benefit decreases 
Table 3. Water resource and pollution data of land use type (EPA, 1991; Li, 2002)

\begin{tabular}{ccccc}
\hline $\begin{array}{c}\text { Land use } \\
\text { type }\end{array}$ & $\begin{array}{c}\text { Water Demand } \\
\left(\mathrm{m}^{3} / \mathrm{yr} / \mathrm{ha}\right)\end{array}$ & $\begin{array}{c}\text { Transformation } \\
\text { Coefficient }\end{array}$ & $\begin{array}{c}\text { Wastewater } \\
\text { (m/yr/ha) }\end{array}$ & $\begin{array}{c}\text { BOD Loading } \\
(\mathrm{kg} / \mathrm{yr} / \mathrm{ha})\end{array}$ \\
\hline Residential & 30,000 & 0.8 & 24,000 & 4,500 \\
Industrial & 25,000 & 0.8 & 20,000 & 6,000 \\
Paddy & 40,000 & 0.4 & 16,000 & 7.4 \\
Dry Farm & 5,000 & 0.4 & 2,000 & 5 \\
Forest & 0 & 0 & 0 & 2 \\
Other & 0 & 0 & 0 & 2 \\
\hline
\end{tabular}

Table 4. Air pollution data of land use type (Yu et al., 2001)

\begin{tabular}{ccccc}
\hline $\begin{array}{c}\text { Land use } \\
\text { type }\end{array}$ & $\begin{array}{c}\text { PM10 } \\
\left(\text { ton } / \mathrm{yr} / \mathrm{km}^{2}\right)\end{array}$ & $\begin{array}{c}\mathrm{SOx} \\
\left(\text { ton/yr } / \mathrm{km}^{2}\right)\end{array}$ & $\begin{array}{c}\text { NOx } \\
\left(\text { ton } / \mathrm{yr} / \mathrm{km}^{2}\right)\end{array}$ & $\begin{array}{c}\text { NMHC } \\
\left(\text { ton } / \mathrm{yr} / \mathrm{km}^{2}\right)\end{array}$ \\
\hline Residential & 81.02 & 332.6 & 203.1 & 1288 \\
Industrial & 56.06 & 13.01 & 6.716 & 360.5 \\
Paddy & 5.369 & 0.009436 & 0.0637 & 4.166 \\
Dry Farm & 5.369 & 0.009436 & 0.0637 & 4.166 \\
Forest & 1.641 & 0.009436 & 0.0637 & 0.3208 \\
Other & 1.641 & 0.009436 & 0.0637 & 0.3208 \\
\hline
\end{tabular}

Table 5. Social and economic data of land use type (EPA, 1991; Li, 2002)

\begin{tabular}{lcc}
\hline Land use type & $\begin{array}{c}\text { Population } \\
\text { (people/ha) }\end{array}$ & $\begin{array}{c}\text { Economic benefit } \\
\text { (NT\$/ha/day) }\end{array}$ \\
\hline Residential & 250 & 270 \\
Industrial & 30 & 410 \\
Paddy & 1 & 8 \\
Dry Farm & 2.5 & 8 \\
Forest & 0.3 & 5 \\
Other & 0.3 & 5 \\
\hline
\end{tabular}

when the decreasing ratio of the area of industrial land use exceeds $5 \%$. This phenomenon occurs because the cost of air pollution abatement decreases slowly when the decreasing ratio of the area of industrial land use exceeds $5 \%$. Furthermore, the concentration of NMHC has met air quality standards with a $5 \%$ reduction, and thus there is no need to abate NMHC load.

For all of the alternatives fitting the concept of sustainable land use management in this study, the optimal alternative is that of decreasing the ratio of the area of industrial land use by $5 \%$. The total benefit of the alternative is $9.30 \times 10^{5} \mathrm{NT} \$$, after considering the costs of water use, water pollution abatement, and air pollution abatement. Meanwhile, this alternative includes three management works as follows.

(1) Increment of available water quantity is $3.50 \times 10^{5}$ $\mathrm{m}^{3}$, which is obtained from the exterior of the basin.
(2) Abatement rate of BOD load is $86 \%$

(3) Abatement rate of PM10 is $31 \%$, while NMHC load does not need to be abated.

According to the results of the case study, the SLUMSD model can be used to evaluate all of the alternatives and help decision-makers in selecting the optimal one. Furthermore, the SLUMSD model can also be used to evaluate the strategies used to allocate all types of land use. Various kinds of management strategies can be simultaneously evaluated by using the SLUMSD model.

\section{CONCLUSION}

This study has developed a sustainable land use management system dynamics model (SLUMSD model) by using the concepts and procedures of system analysis. The SLUMSD model can help decision makers to integrally and systematically consider the components and interactions in land use management. The results overcome the defects caused by individual consideration of the economic, social, and environmental influences in the current land use management framework.

Development of the SLUMSD model is based on the concept of sustainable land use management. This study uses the concept of sustainable development to identify the principles of sustainable land use management that must meet the needs of humans, keep within carrying capacity, and use systems thinking in the procedure. With systems thinking, this study has developed dynamics of sustainable land use 

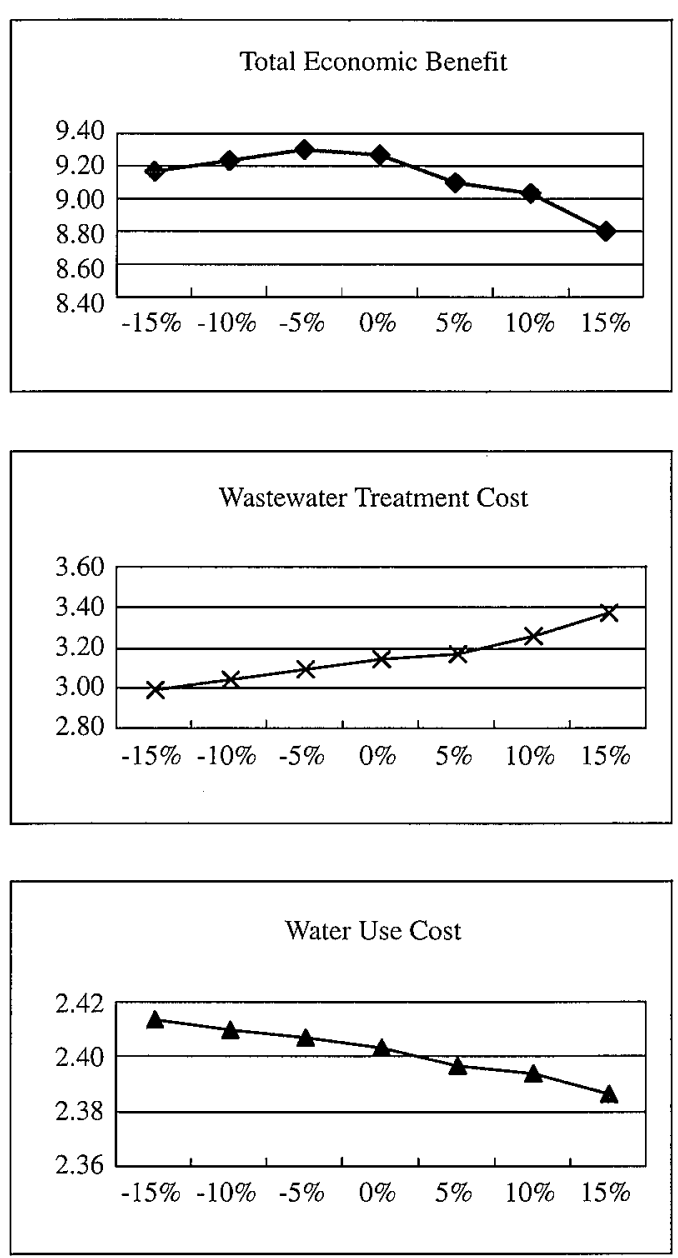

Fig. 8 Benefits and costs of land use management strategies
Land Use Benefit
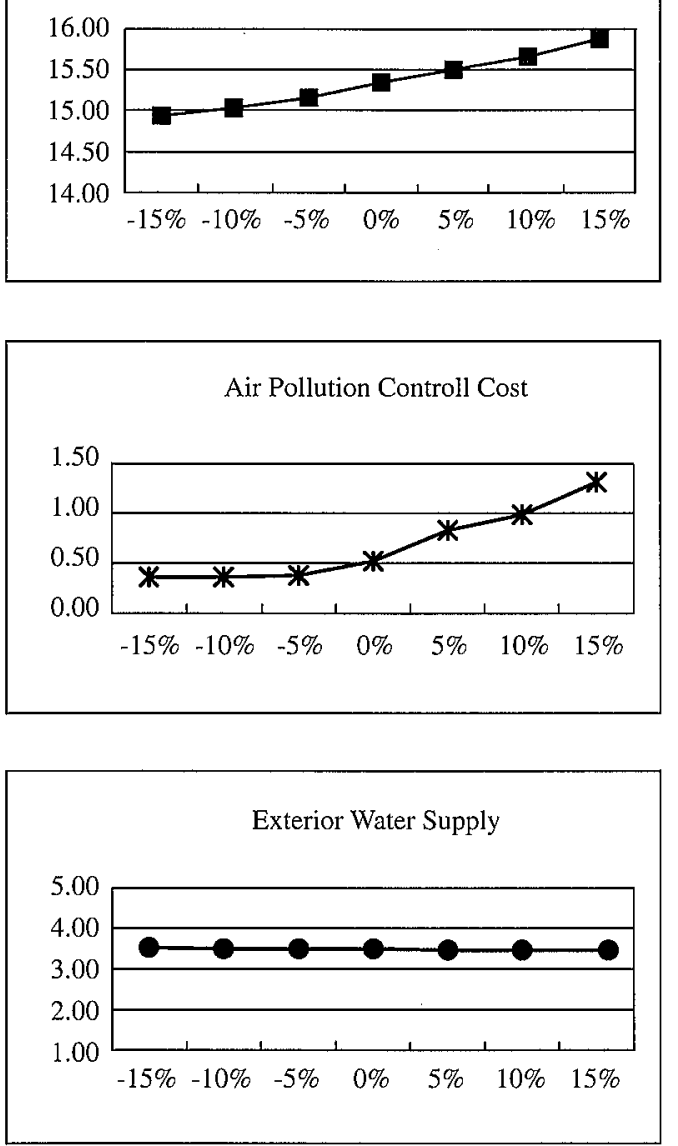

management in a river basin, which considers human activities, land resources, water resources, and air resources integrally. The components and interactions in the dynamics have been identified in this study. Meanwhile, this study has established a conceptual dynamics framework of sustainable land use management by using the concept of driving forcestate-response (D-S-R). From the framework, decision makers can obtain suitable alternatives through integral and iterative procedures.

This study uses Vensim software and the concept of object-oriented programming (OOP) to develop the SLUMSD model. The SLUMSD model can be used to show the influencing components in the causal loops. Furthermore, the SLUMSD model employs sliders to modify the input data in various management plans. This function makes the model user understand how input data variation causes corresponding variation in the analytical results. Additionally, the policy optimization function is provided to optimize the solution.

The Nankan river basin, located in northern
Taiwan, is used as a case study to illustrate the capability of the SLUMSD model. Initially, the SLUMSD model can be used to assess the sustainability of the basin at the present condition of land use. Due to the lack of a sustainable land use management plan, sustainable development is difficult to achieve in the basin given present land use conditions.

In the allocation of industrial land use area, this study uses the SLUMSD model to generate different alternatives fitting the concept of sustainable land use management. The optimal alternative is a $5 \%$ decrease in the area of industrial land use after surveying all data variations. The optimal alternative includes a $3.50 \times 10^{5} \mathrm{~m}^{3}$ importation of exterior water, an $86 \%$ BOD load abating rate, and a $31 \%$ PM10 load abating rate. However, different spatial allocations of the same variation of industrial area may result in quite different environmental conditions. Different allocating methods of water resources and air resources may also influence the alternatives.

Analytical results indicate that the SLUMSD model developed in this study has clearly identified 
the interactions among components of a river basin environment system that are relevant to sustainable land use management. During sustainable land use management planning, decision-makers can use the SLUMSD model to obtain variations of all components with different alternatives. Appropriate sustainable land use management decisions can be made by using the SLUMSD model to iteratively modify the alternatives.

\section{REFERENCES}

Buller, H., 1996, "Towards Sustainable Water Management: Catchment Planning in France and Britain," Land Use Policy, Vol. 13, No. 4, pp. 289-302.

Chen, C. H., Liaw, S. L., Wu, R. S., Chen, Q. L., and Chen, J. L., 1997, "Development of a Decision Making Theory and a Decision Support System for River Basin Water Management," Proceedings of the National Science Council, R.O.C., Part A, Physical science and engineering, Vol. 21, No. 5, pp. 389-409.

Chen, C. H., Wu, R. S., Liaw, S. L., Sue, W. R., and Chiou, I. J., 2000, "A Study of Water-Land Environment Carrying Capacity for a River Basin," Water Science and Technology, Vol. 42, No. 3-4, pp. 389-396.

Environmental Protection Administration, 1991, Planning of Water Pollution Control for Shinjei River, Laujei River, Nankan River, and Shirtzi River, Environmental Protection Administration, Taipei, Taiwan, R.O.C..

The International Union for Conversation of Nature and Natural Resources/United Nations Environment Programme/World Wildlife Fund, 1991, Caring for the Earth: A Strategy for Sustainable Living, The International Union for Conversation of Nature and Natural Resources/United Nations Environment Programme/World Wildlife Fund, Gland, Switzerland.

Li, M. Y., 2002, "Development of a System Dynamics Model for River Basin Water Management", Master Thesis, Chungli, Taiwan, R.O.C..

Li, X., Peterson, J., Liu, G. J., and Qian, L., 2001, "Assessing Regional Sustainability: the Case of Land Use Land Cover Change in the Middle Yiluo Catchment of the Yellow River Basin, China," Applied Geography, Vol. 21, No. 1, pp. 87-106.

Liu, C. Z., 1997, "Rural Land Use Planning and Management in Taiwan," Journal of Agriculture and Forestry, Vol. 46, No. 2, pp. 15-28.

Luxem, M., and Bryld B., 1997, "Introductory Box: The CSD Work Programme on Indicators of Sustainable Development," Sustainability Indicators: A report on the Project on Indicators of
Sustainable Development, B. Moldan, S. Billharz, and R. Matravers (ed.), John Wiley \& Sons Ltd, England, pp. 6-12.

Miyamoto, K., Udomsri, R., Sathyaprasad, S., and Ren, F., 1996, “A Decision Support System for Integrating Land Use, Transport and Environmental Planning in Developing Metropolises," Computers, Environment, and Urban Systerns, Vol. 20, No. 4/5, pp. 327-338.

Mortensen, L. F., 1997, "Box 1D: The Driving ForceState-Response Framework Used by CSD," Sustainability Indicators: A report on the Project on Indicators of Sustainable Development, B. Moldan, S. Billharz, and R. Matravers (ed.), John Wiley \& Sons Ltd, England, pp. 47-53.

Nevers, N. D., 1995, Air Pollution Control Engineering, McGraw-Hill, New York, NY, U.S.A.

Senes, G., and Toccolini, A., 1998, "Sustainable Land Use Planning in Protected Rural Areas in Italy," Landscape and Urban Planning, Vol. 41, No. 2, pp. 107-117.

Senge, P. M., 1990, The Fifth Discipline: The Art and Practice of the Learning Organization, Doubleday, New York, NY, U.S.A..

Streeter, H. W., and Phelps, E. B., 1925, "A Study of the Pollution and Natural Purification of Ohio River," Public Health Bulletin, 146, U.S. Public Health Service, Washington, D.C., U.S.A..

Teague, W. R., 1996, "A Research Framework to Achieve Sustainable Use of Rangeland," Agriculture, Ecosystems and Environment, Vol. 57, No. 2-3, pp. 91-102.

van Ittersum, M. K., Rabbinge, R., and van Latesteijn, H. C., 1998, "Exploratory Land Use Studies and Their Role in Strategic Policy Making," Agricultural Systems, Vol. 58, No. 3, pp. 309-330.

World Commission on Environment and Development, 1987, Our Common Future, Oxford University Press, Oxford, U.K..

Williams, K., 1999, "Urban Intensification Policies in England: Problems and Contradictions," Land Use Policy, Vol. 16, No. 3, pp. 167-178.

$\mathrm{Yu}$, C. H., Lin, C. F., and Chen, C. H., 2001, "Development of an Air Pollution Evaluation System by Linking Air Pollution Total Quantity Control and Land Use Management," Journal of the Chinese Institute of Engineers, Vol. 24, No. 5, pp. 619 628.

Zander, P., and Kächele, H., 1999, "Modelling Multiple Objectives of Land Use for Sustainable Development," Agricultural Systems, Vol. 59, No. 3, pp. 311-325.

Manuscript Received: July. 11, 2002 Revision Received: Nov. 29, 2002 and Accepted: Feb. 7, 2003 